\title{
Por um Ensino investigativo: concepções docentes acerca da pesquisa como atitude e como estratégia pedagógica
}

\section{For an investigative teaching: teachers' conceptions about research as a professional attitude and as a pedagogical strategy}

Cleise Helen Botelho Koeppe (koeppe@ufrgs.br)

Universidade Federal do Rio Grande do Sul (UFRGS)

\author{
Marcus Eduardo Maciel Ribeiro (profmarcus@yahoo.com.br) \\ Instituto Federal Sul-rio-grandense (IFSUL) \\ Programa de Pós-graduação em Ensino de Ciências Exata - PPGECE (FURG)
}

Luciana Calabró (luciana.calabro@ufrgs.br)

Universidade Federal do Rio Grande do Sul (UFRGS)

Resumo: A formação do professor pesquisador reflexivo é importante para a qualificação da Educação Básica Brasileira. O presente artigo, derivado de uma pesquisa de doutoramento, tem por objetivos analisar os fatores que influenciam, ou não, a participação efetiva de docentes em uma investigação e ainda, as vantagens e dificuldades que os docentes enfrentam na implementação da pesquisa como princípio educativo. Os colaboradores são 27 profissionais em exercício em diversas áreas e níveis de atuação na Educação Básica, dos estados de Santa Catarina e Rio Grande do Sul. De cunho qualitativo, o artigo apresenta dados referentes à formação desse grupo de pesquisa e seus discursos, analisando os motivos que levam docentes a assumirem os pressupostos da pesquisa como atitude profissional e pedagógica. Conclui-se que os professores em exercício ainda encontram dificuldades em apropriar-se dos pressupostos de pesquisa, tanto como atitude educativa, quanto como pedagógica e que, as formações continuadas podem colaborar para essa mudança de concepção.

Palavras-chave: professor pesquisador; pesquisa; motivação à pesquisa; participação docente

Abstract: It's important for the Brazilian Basic Education that the teachers develop a brainwork about their professional exercise. This article, part of a doctoral research, intend to analyze some elements that influence, or not, the teachers engagement in a research experience and also, the advantages and difficulties that teachers face when implementing the research as a principle educational. The actors are 27 professionals in practice in several areas and levels of performance in Basic Education, from the states of Santa Catarina and Rio Grande do Sul. Describing a qualitative experience, the article presents data referring to the formation of this research group and their speeches, analyzing the reasons that lead teachers to assume the research assumptions as a professional and pedagogical attitude. It is concluded that the operative teachers still find it's difficult to take ownership of the posture and pedagogical research in their practice, and that the continuous training can collaborate for these conceptions' changing.

Keywords: research professor; search; motivation to research; teacher participation 


\section{INTRODUÇÃO}

Ensinar é busca, dúvida, constatação e intervenção, enfim, ensinar é investigar a realidade, modificando-a. Freire (1996, p. 14) vincula a pesquisa à natureza docente, ao afirmar: "O de que se precisa é que, em sua formação permanente, o professor se perceba e se assuma, porque professor, como pesquisador". Entretanto, esse entendimento parece inexistente aos professores em exercício ainda hoje. Para Estebán e Zaccur (2002) isso se deve à dificuldade dos docentes em se assumirem também, produtores de um conhecimento sustentado pela problematização e reflexão sobre sua prática.

Em resposta a esse cenário, surge, nas décadas de 1980/90, um movimento no sentido de alavancar a formação de um docente reflexivo autônomo e emancipado (CONTRERAS, 2002), aquele que, por ser capaz de pesquisar sua realidade educacional (SCHÖN, 2000; ANDRÉ et. al. 2010), faz uso de práticas reflexivas críticas para alterar seu cotidiano escolar, sua comunidade e as estruturas sociais (LISTON; ZEICHNER, 1991). Ainda que atualmente existam variadas interpretações e divergências para o conceito "professor reflexivo" balizamos nossa discussão na definição proposta por Zeichner (1998) segundo a qual, a reflexão da prática docente mobiliza os professores ao desafio de superar a reprodução inconsciente e passiva do status quo. Moreira (1988, p. 43) associa reflexão e pesquisa docentes quando afirma: "pesquisar em ensino é sobretudo refletir criticamente a respeito da prática docente."

Pode-se pensar nas concepções de professor pesquisador e reflexivo, como sustentáculos para a proposta do Educar pela pesquisa (DEMO, 1996; MORAES; GALIAZZI; RAMOS, 2002). Popular no meio acadêmico, esta proposta serve como apoio metodológico e didático para a formação de licenciandos, originando o desenvolvimento de múltiplas investigações, que atestam sua eficácia para uma aprendizagem consistente e significativa, pois, institucionaliza a pesquisa como princípio educativo. Entretanto sua aplicação no cotidiano escolar, em variados níveis da Educação Básica, é incipiente.

Perante essa realidade, uma das autoras, que também leciona na Educação Básica, empreende uma pesquisa de doutoramento na qual busca desenvolver uma investigação 
em parceria com professores-pesquisadores. A constituição desse grupo de pesquisa se mostrou sujeita a fatores que influenciaram positiva e negativamente a participação efetiva dos professores e ainda abriu caminho para a discussão a respeito do uso de pesquisa como estratégia educativa. O presente artigo tem por objetivo geral analisar os fatores que influenciam, ou não, a participação efetiva de docentes em uma investigação, na qual atuariam como pesquisadores-parceiros, implementando os pressupostos teóricos do Educar pela pesquisa, em sua prática cotidiana. Dessa forma, duas perspectivas são discutidas neste artigo: a pesquisa como atitude docente e a pesquisa como estratégia de ensino na sala de aula. As dificuldades em formar esse grupo de pesquisa deram origem à questão: Quais fatores influenciam, positiva ou negativamente, a participação docente em uma pesquisa de ensino? E as discussões a respeito de processos de investigação, originaram a segunda questão: Como os professores entendem pesquisa escolar e quais os empecilhos que se apresentam para sua aplicação enquanto prática cotidiana docente?

Partindo desse entendimento, este artigo aborda duas vertentes sobre a pesquisa docente na Educação Básica, fundamentadas em dois objetivos específicos: identificar quais fatores influenciam a atitude pesquisadora docente e sua consequente atuação efetiva como pesquisador e, averiguar como os professores entendem a pesquisa escolar enquanto estratégia de ensino, bem como, os empecilhos que se apresentam à sua aplicação como tal.

\section{REFERENCIAL TEÓRICO}

Apesar do aparente consenso acadêmico em relação à importância do professor reflexivo e pesquisador na Educação Básica (MOREIRA, 1988; OLIVEIRA; CHAPANI, 2017), os profissionais em exercício nestas etapas de ensino permanecem como técnicos reprodutores de conhecimentos desenvolvidos por outrem (OLIGURSKI; PACHANE, 2010). Como trazer para a sua prática, a pesquisa como princípio educativo se, o próprio professor não possui, nem domina, o hábito de pesquisar?

Estudantes e professores conferem à pesquisa um status decorrente de um discurso que reforça seu caráter reservado a poucos privilegiados, encastelados em seus saberes (LÜDKE; ANDRÉ, 1986). Segundo Demo (1990, p. 77): “Um professor de $1^{\text {o }}$ 
$\mathrm{Grau}^{1}$ teria o maior constrangimento em ver-se colocado como cientista ou pesquisador, porque foi domesticado na universidade a aprender imitativamente e a atuar na escola como mero instrutor”. De acordo com Moreira (1988), boa parte dessa interpretação se deve a uma pretensa sofisticação metodológica, historicamente conferida ao processo investigativo. Sofisticação esta, acessível atualmente aos professores, mediante o uso de recursos tecnológicos disponíveis.

Reprodutores de um discurso pedagógico, que limita sua prática à elaboração de um currículo "aproveitável", transmitindo um "saber externo" e angustiados com os efeitos contrários ao esperado (GARCIA, 2009), muitos professores ainda não entendem a pesquisa como, um dispositivo cultural que, transforma e subjetiva educadores em indivíduos conscientes de sua própria capacidade, capazes de contribuir para uma educação de qualidade (LARROSA, 2011).

Superar essa concepção, reconhecendo-se como alguém capaz de questionar, analisar e argumentar suas ações profissionais, talvez seja o primeiro passo para a gênese de um professor-pesquisador autônomo e crítico ciente de seu papel na sociedade contemporânea.

\section{a. A PESQUISA COMO ATITUDE DOCENTE}

Bachelard $(1996 ; 1970 ; 2003)$ defende a mobilidade do conhecimento, para ele, o conhecimento não é um acúmulo de informações, mas construção idiossincrática, questionadora e racional decorrente do diálogo entre o mundo de ideias e fatos e a imaginação, que levam o indivíduo à "sobre humanidade", em constante retificação dos saberes consolidados, relativos não só ao objeto, como também ao próprio sujeito. $\mathrm{O}$ professor reflexivo, ao analisar sua prática, dinamiza e qualifica o conhecimento escolar em todas as instâncias educativas, além de sair da estagnação e passividade características daquele professor transmissor de conhecimentos acumulados pela humanidade (LOGUERCIO; DEL PINO, 2003).

O professor, enquanto exercita o pensar sua prática, elabora hábitos de problematização, análise e regulação com autonomia, de maneira a transformar ações e saberes, mas sobretudo, sua identidade como profissional da educação (LARROSA,

${ }^{1}$ Forma como era chamado o Ensino Fundamental no Brasil quando da escrita do texto referência. 
2011). Desse modo, mesmo que não se reconheça, já é um professor-pesquisador como definia Freire (1996). Nunes (2008) afirma que, ao desenvolverem atitude pesquisadora, os professores ampliam a consciência crítica de sua prática profissional, assumindo maior responsabilidade por suas ações educativas, fundamentadas em pressupostos teórico-empíricos ao invés de aplicações decorrentes do ensaio-erro, histórico pessoal ou "modismos".

Incentivar os professores à pesquisa é transcender abismos existentes entre conhecimentos acadêmicos e escolares, respeitando com ética e paridade as produções docentes. Os professores geram conhecimentos não apenas práticos ou superficiais e muitos se opõem à visão negativa e acomodada do professor desinteressado em mudar sua prática (ZEICHNER, 1998). Entretanto, as formações iniciais e continuadas, não contemplam esta visão. Via de regra, as graduações alimentam o viés tecnicista e mecânico da tradicional educação para o magistério, disponibilizando pouco preparo específico às ações investigativas (LÜDKE, 2001; NUNES, 2008).

Há que se fazer justa exceção ao Programa Institucional de Bolsa de Iniciação à Docência -PIBID-, implementado pelo Decreto $n^{\circ}$ 7.219/2010 (BRASIL, 2010), que desde 2008 vem ampliando a perspectiva educacional docente para a pesquisa, na formação inicial de professores. Reflexo ainda não perceptível em formações continuadas, que atendem professores em exercício, alguns já há muito, distantes dos bancos escolares como aprendizes.

A Formação docente, seja ela inicial ou continuada, é fator significativo para a gênese do professor pesquisador e reflexivo. Torna-se pois, importante salientar que "a melhor maneira de avaliar a solidez das ideias é ensiná-las, seguido nisso o paradoxo que se ouve com tanta frequência nos meios universitários: ensinar é a melhor maneira de aprender (BACHELARD, 1977, p. 19)", e consequentemente: para ensinar/aprender, é necessário saber fazer, transformando assim, a escola em um ambiente socialmente ativo, "todos se fazendo a um só tempo, estudantes e professores, sempre reelaborando o conhecimento (LOPES, 1993, p. 326).”

\section{b. A PESQUISA COMO ESTRATÉGIA DE ENSINO}

O parecer CNE/CP 009/2001 (BRASIL, 2001, p. 36) manifesta os avanços desse movimento pela pesquisa como estratégia de ensino na Educação Básica ao estabelecer que: “[...] é papel do professor da Educação Básica desenvolver junto a seus futuros 
alunos postura investigativa. Assim, a pesquisa constitui um instrumento de ensino e um conteúdo de aprendizagem na formação, especialmente importante [...]”.

Legalmente este decreto, institui a prática investigativa na sala de aula como instrumento e conteúdo de aprendizagem, capaz de potencializar o ensino críticoanalítico e significativo. Todavia para que isso ocorra exige, por parte do professor novos olhares e ações, superando a habitual transmissão de conceitos memorizáveis, enquanto traz o ensino pela pesquisa, o aluno, a discussão e a capacidade de argumentação para o epicentro do processo de ensino-aprendizagem (FÁVERO; TONIETO, 2020).

O Educar pela pesquisa vem contribuir com esta perspectiva de ensino, pois, de acordo com Moraes; Galiazzi e Ramos (2002), ao se apoiar em princípios básicos da metodologia científica, busca desenvolver o conhecimento escolar por meio da problematização, da argumentação e da comunicação. Converte dessa forma, a pesquisa em estratégia didática cotidiana livrando-se da expectativa arcaica de uma pesquisa feita por especialistas distantes do contexto escolar, e auxilia os estudantes a compreenderem-na como independente de aspectos fantasiosos ou extravagantes (DEMO, 1996) do senso comum.

Kierepka e Zanon (2019) destacam a importância de se formar um coletivo docente para argumentar e refletir de maneira singular suas respectivas práticas, intercorrendo problematizações relevantes como subsídios a modificações consistentes em/suas próprias ações pedagógicas. A pesquisa como princípio educativo é um processo eminentemente social e político que promove o desenvolvimento de uma capacidade crítica, ética e autônoma dos sujeitos (DEMO, 1996), instrumentalizando-os a intervir positivamente em sua realidade.

\section{CAMINHOS METODOLÓGICOS}

Uma pesquisa que se desenvolve a partir das relações educacionais em suas dimensões humanas: aspirações, valores e atitudes de grupos docentes específicos de professores (GERHARDT; SILVEIRA, 2009) concentrando-se em aspectos subjetivos não quantitativos (MINAYO, 1994) como essa, pode ser definida como uma pesquisa qualitativa de cunho empírico.

Mesmo sendo parte de uma pesquisa de doutoramento, com as características acima descritas, que tem por proposta o desenvolvimento de uma pesquisa-ação, este artigo se propõe à análise de concepções dos docentes que para ela colaboraram, assim 
sendo, este trabalho caracteriza-se como um Estudo de caso narrativo de situações e opiniões que emergiram durante o desenvolvimento da pesquisa-ação (TRIPP, 2005).

\section{a. OS COLABORADORES DA PESQUISA}

Participam dessa pesquisa, 27 profissionais docentes que convivem, ou conviveram, com a professora-pesquisadora em seu cotidiano escolar e acadêmico, distribuídos pelas redes de ensino de Santa Catarina (17), e do Rio Grande do Sul (10). Constituem um grupo docente diversificado quanto às áreas de atuação e à formação acadêmica, descritas em gráficos anexados ao texto, pois, esses fatores são utilizados como informações para a discussão das categorias decorrentes da análise dos dados.

A pesquisa encontra-se amparada pelo parecer número 22203 do Comitê de ética da UFRGS. Cada participante escolheu um pseudônimo, com o qual será identificado ao longo do texto, preservando seu sigilo e anonimato, e assinou o Termo de consentimento livre esclarecido - TCLE - para que suas representações sejam utilizadas. Suas falas encontram-se inseridas no texto em itálico para diferenciá-las das citações dos teóricos que apoiam as discussões.

\section{b. O CORPUS DE PESQUISA}

Os dados foram coletados por questionários digitais de perguntas abertas e gravações de entrevistas, posteriormente transcritas, permitindo a organização de um conjunto de informações sobre suas concepções acerca de serem também, pesquisadores da própria prática, e como compreendem a pesquisa enquanto princípio educativo. $\mathrm{O}$ artigo discute as categorias: Influência da formação inicial, da área de atuação e da titulação para a motivação docente em participar de processos de pesquisa, Fatores que motivam a participação docente em ações investigativas, Fatores que dificultam a participação docente em ações investigativas, Concepções docentes a respeito da pesquisa como estratégia de ensino e Desafios da utilização da pesquisa em sala de aula, as quais, emergiram da Análise Textual Discursiva (MORAES;GALIAZZI, 2007) empreendida como metodologia de análise desses dados.

Para organizar o fluxo do texto, os dados foram tabulados e, alguns deles, sistematizados em gráficos do tipo "pizza" enquanto outros, em gráficos do tipo "nuvem de palavras". Encontram-se apresentados em forma de figuras no texto a seguir, e servem de base para a devida discussão teórico-empírica.

\section{DISCUSSÕES}

a.

\section{POR UM PROFESSOR PESQUISADOR E REFLEXIVO}


Habitualmente, a atitude investigativa do professor da Educação Básica obedece à uma concepção tradicional, segundo a qual, prática e teoria apresentam dependência externa, ou seja, a despeito do ambiente escolar ser o foco das investigações, nele se empreende a coleta dos dados a serem analisados e teorizados por pesquisadores acadêmicos, em ambientes alheios à realidade da escola propriamente dita (MOREIRA, 1988). Anita, atuante nas séries iniciais do Ensino Fundamental, quando convidada a participar do projeto de pesquisa, afirma: "quero participar sim, adoro ser cobaia", com esta fala, dispõe a condução da investigação nas mãos da professora-pesquisadora, evidenciando distanciamento entre os saberes teóricos provenientes da academia, e os práticos por ela elaborados (OLIGURSKI; PACHANE, 2010; ZEICHNER, 1998). Entretanto, segundo Fontana e Fávero (2013), o saber prático produzido pelo professor, quando refletivo à luz do saber teórico disponibilizado pela academia, promove o aumento de seu conhecimento investigativo.

Demo (1996) sugere a área de formação e Leite, Magalhães Jr. e Rodrigues (2018) citam o tempo de docência, como possíveis fatores que motivam professores à atitude investigativa. A essas duas sugestões do referencial teórico, acrescentamos o item titulação, para analisar a primeira categoria: Influência da formação inicial, da área de atuação e da titulação para a motivação docente em participar de processos de pesquisa, os dados fornecidos pelos colaboradores da pesquisa encontram-se descritos nos gráficos da figura 1 :

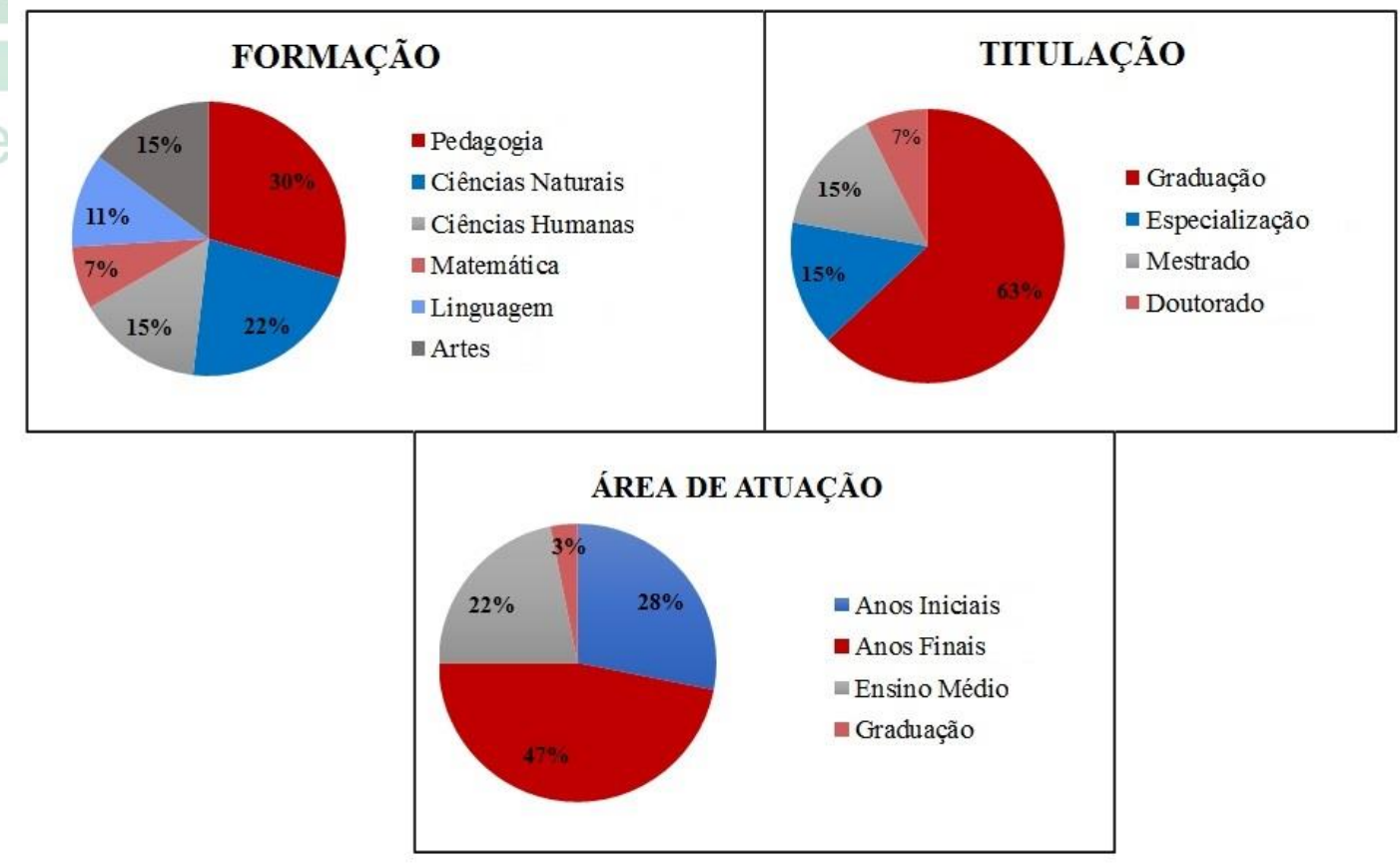

Figura 1 - Características formativas e profissionais do grupo de professores colaboradores

Dentre os 27 integrantes, a maioria, 17, possui graduação. Dois são doutores e os oito restantes dividem-se equitativamente entre especialização e mestrado. Estes dados, 
apontam para uma possível falta de familiaridade com os pressupostos teórico-práticos de uma pesquisa (LEITE; MAGALHÃES; RODRIGUES, 2018), o que pode demandar dificuldades de engajamento, mas também, em alguns casos, motivação. Driver et. al (1999) relatam situações, nas quais professores, mesmo sem intimidade com as prerrogativas metodológicas de uma investigação, se reconhecem como pesquisadores e aprendizes.

Quanto à atuação e à formação profissional, 15 lecionam nos Anos Finais do Ensino Fundamental, e são licenciados em disciplinas diversas. Dentre estes, quase todos atuam, também, no Ensino Médio. Dos que lecionam nas Séries Iniciais, apenas uma, que se encontra cursando doutorado, não é Pedagoga, mas graduada em Ciências Biológicas. Dentre os(as) nove Pedagogos(as), quatro possuem Especialização: duas em Neuropedagogia, um em Tecnologias da Informação, e uma em Alfabetização.

Tal realidade permite confirmar que a pesquisa encontra-se mais presente nos cursos de licenciaturas específicas, despertando em seus egressos o interesse em permanecer pesquisando. "Me confundo com essas coisas de metodologia. Na faculdade, a gente lia os livros e fazia resenha", a fala de Antonieta - Pedagoga confirma as afirmações de Lüdke (2001) sobre a acanhada importância conferida à formação para pesquisa pelos docentes, graduados em cursos de formação para o magistério na Educação Básica. Em contrapartida, os licenciados, e professores dos níveis posteriores de ensino, demonstram maior intimidade com a pesquisa, muitos afirmando sentir prazer em pesquisar, corroborando a assertiva de Piti - Matemática: "gosto disso de pesquisar".

A figura 2 sintetiza as palavras mais frequentes no discurso desses colaboradores de pesquisa, em resposta à pergunta: Por que você está interessado em participar desta pesquisa? Suas declarações são discutidas na categoria: Fatores que motivam a participação docente em ações investigativas. 


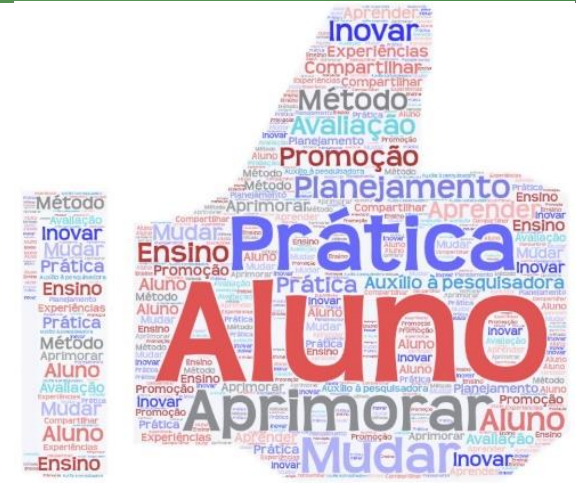

Figura 2 - Palavras recorrentes no discurso dos professores sobre motivação à pesquisa.

São três, as palavras que mais se repetem quando o professor se dispõe a pesquisar suas atuações profissionais: aluno (25), prática (21) e aprimorar (19) geralmente, agregam a estas, a palavra ensino (3). Tais palavras apontam para o aluno como motivação para o aprimoramento da prática docente. Demonstrando que, para esses professores, o aluno é o centro e objeto de suas atenções pedagógicas. O professor em exercício reconhece a necessidade de aprimorar sua prática de ensino, adquirindo assim, mais subsídios que propiciem melhorias para a aprendizagem discente.

Por outro lado, as palavras: planejamento (13), método (7) e experiências (6) apareceram articuladas com as palavras aprimorar e aprender (8), como exemplificado pela fala de Jacira: "A gente precisa participar dessas coisas para atualizar nosso planejamento, aprendendo novas experiências e métodos desenvolvidos nas faculdades, eles não param né?"; ou de Zuzu: "É bom participar (da pesquisa), estou afastada há muito tempo da universidade”. Reforçando o entendimento corrente de que pesquisa em ensino não pertence ao âmbito institucional escolar (ANDRÉ, 2010).

Dessa forma, posicionam-se como colaboradores de uma investigação, academicamente orientada, na qual apropriam-se das dimensões teórico-metodológicas da pesquisa. A compreensão de que são elementos constitutivos deste processo, encontra-se subsumida em sua prática e na ansiedade em colaborar para as atividades alheias. Esses professores se disponibilizaram a colaborar com uma pesquisa, imbuídos pela crença da abordagem tradicional para a pesquisa em educação, de "fora pra dentro", mediada por um perito externo ao seu cotidiano e, acreditando que este saber externo inovador, pode apresentar-se como resposta aos seus anseios (ENGEL, 2000). A promoção de momentos interativos permite que se apropriem de novas práticas, subsidiando suas ações e aprendizagens (DRIVER et. all. 1999). 
Compartilhar (6), inovar (4), aprender (8) e mudar (10) relacionam-se ao conceito de professor-pesquisador, envolvem aprofundamento teórico e discussões críticas a respeito da prática docente. Como foram indicadas por uma quantidade significativa dos participantes, alertam para o fato de que essa concepção investigativa começa a ser considerada pelos docentes em exercício. Tarsila assegura: "Conversar (sobre as atividades) é muito bom, aprendemos coisas que nem nos dávamos conta", evidenciando a importância conferida pelo grupo, ao compartilhamento de saberes como uma das vantagens da pesquisa docente (KIEREPKA; ZANON, 2019).

Um fator relevante a se considerar é o item promoção (18), aproximadamente $50 \%$ dos graduados encontra-se envolvido em pesquisa por iniciativas pessoais, cursam doutorado, mestrado ou especializações, ou ainda, participam de processos seletivos de pós-graduação, intencionando alçar titulações para promoção nos quadros de carreira do magistério público. Nicolau - Geógrafo, com a fala: "preciso fazer um mestrado para ganhar promoção" expõe essa tendência do grupo. São licenciados em diversas áreas e suas pesquisas envolvem temáticas relacionadas à disciplina de origem, não especificamente às áreas de Ensino ou Educação.

Habitualmente, o conceito de avaliação (8) é vinculado à reflexão acerca da prática pedagógica e à participação em pesquisas que forneçam inovações nesta esfera pedagógica. Em algumas situações, os participantes associam pesquisa, reflexão e avaliação, como revelam as afirmações de Marie e Fermat:

Gosto de participar de pesquisas pois assim, descubro novas formas de despertar o interesse dos meus alunos. Aliás é nisso que penso e avalio com frequência: se o que estou tratando vai ser realmente útil para a vida do meu aluno (MARIE).

Geralmente participo de pesquisas sobre formas de avaliação. Quando penso na minha maneira de trabalhar, me preocupa desenvolver aulas em que os alunos compreendam o processo, nunca a memorização por si só. Mas tenho imensa dificuldade em avaliar, pois sinto que não reflete o que eu deveria saber sobre os alunos. E as pesquisas me ajudam a descobrir maneiras mais palpáveis de avaliar (FERMAT).

A expressão: auxílio à pesquisadora (7), decorrente de afinidades pessoais que superam interesses pedagógicos, revelam uma motivação que pode surtir efeito negativo para a adesão às pesquisas. Alguns colaboradores, por suas afinidades profissionais com a pesquisadora, sentiram-se constrangidos em negar formalmente o convite para participar da pesquisa, Cacá, inclusive, afirmou que participaria apenas "para ajudar a pesquisadora”.

Desistências sucessivas e o pouco envolvimento dos colaboradores nas etapas teóricas iniciais da investigação trouxeram à tona a terceira categoria de análise: Fatores 
que dificultam a participação docente em ações investigativas. As palavras mais repetidas como justificativas para essas ações encontram-se compiladas na figura 3:

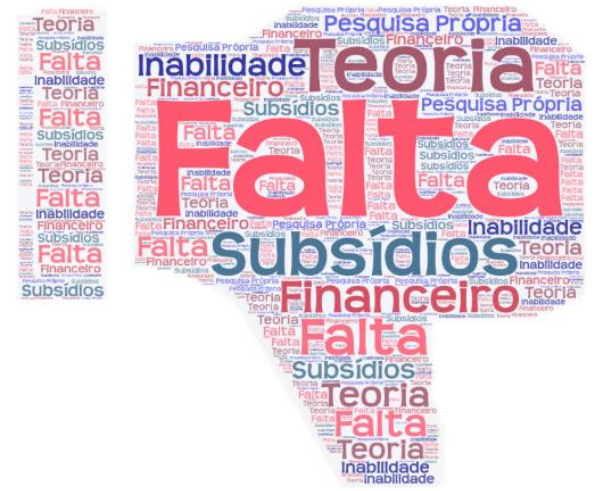

Figura 3 - Palavras recorrentes no discurso dos professores sobre empecilhos à pesquisa.

Palavras como falta (23), tempo (19), teoria (14), subsídios (11) e financeiro (10) expressam os principais empecilhos à atitude investigativa docente. Corroborando as dificuldades cotidianas de um professor da Educação Básica, a carência de incentivos financeiros, de subsídios teóricos atualizados e convenientes à realidade escolar e a sobrecarga de trabalho repercutem como os principais obstáculos para a formação de um professor-pesquisador que persista em atitude investigativa.

A propósito, a condição falta de tempo foi a mais presente nas falas dos participantes, como impedimento à participação na pesquisa. Os participantes afirmaram que exigências profissionais tais quais: preenchimento de documentos, reuniões pedagógico-administrativas, planejamento de atividades, encerramento de ano letivo dentre outras, acabam por ocupá-los demasiadamente, fazendo com que não sobre tempo para dedicarem-se aos processos de desenvolvimento da pesquisa. Muitos alegaram também, a necessidade de descanso em função da sobrecarga de trabalho, decorrente das muitas horas requisitadas pela docência (OLIVEIRA; CHAPANI, 2017).

Cortizo (2012) menciona essas situações como fatores que influenciam, de forma negativa, tanto o cotidiano profissional quanto a participação protagonista em grupos de pesquisa, provocando ainda, angústia e desalento aos professores. Camila declarou ter vontade de participar mais, porém, apenas depois de concluir as atividades planejadas para eventos culturais das escolas em que atua, revelando animação para a participação na pesquisa e ao mesmo tempo, angústia pela sobrecarga de trabalho em que se encontra.

Alguns professores, manifestaram a expressão pesquisa própria (5) como fator perturbador da participação em uma ação investigativa. Quatro desses, envolveram-se Recebido em: $01 / 09 / 2020$ 
nas etapas iniciais e discussões sobre metodologia de pesquisa e posteriormente, afastaram-se, alegando necessidade em dedicar-se à sua própria pesquisa. Todavia uma professora, permaneceu no projeto, incorporando tópicos discutidos com a professorapesquisadora à sua própria pesquisa.

Casos de percepções convencionais docentes, relativas à pesquisa educacional, expressam-se na palavra inabilidade (2), esses participantes declararam reconheceremse inábeis para lidar com questões teórico-metodológicas da pesquisa, disponibilizandose a aplicar de maneira prática em suas salas de aula as propostas, fornecendo dados para o desenvolvimento da pesquisa, sem contudo, envolverem-se em discussões e considerações, consolidando a concepção tradicional do professor receptor passivo da pesquisa desenvolvida na academia (ZEICHNER, 1998; MOREIRA, 1988; ENGEL, 2000; OLIVEIRA; PACHANE, 2010).

\section{b. PELA PESQUISA COMO PRÁTICA DOCENTE}

Considerando que a pesquisa em sala de aula envolve uma série de atores, dentre eles, estudantes e professores da Educação Básica, ocorre a necessidade de investigar como os professores se apropriam dessa proposta didático-metodológica e a empregam em sua prática pedagógica, e principalmente, os motivos pelos quais essa prática docente parece ainda, não ser popular nos diversos níveis da Educação Básica.

A figura 4 sintetiza percepções dos participantes, relativas à utilização da pesquisa como princípio educativo. Tais palavras serviram de ponto de partida para as discussões da quarta categoria: Concepções docentes a respeito da pesquisa como estratégia de ensino, que emergiu da análise dos dados. 


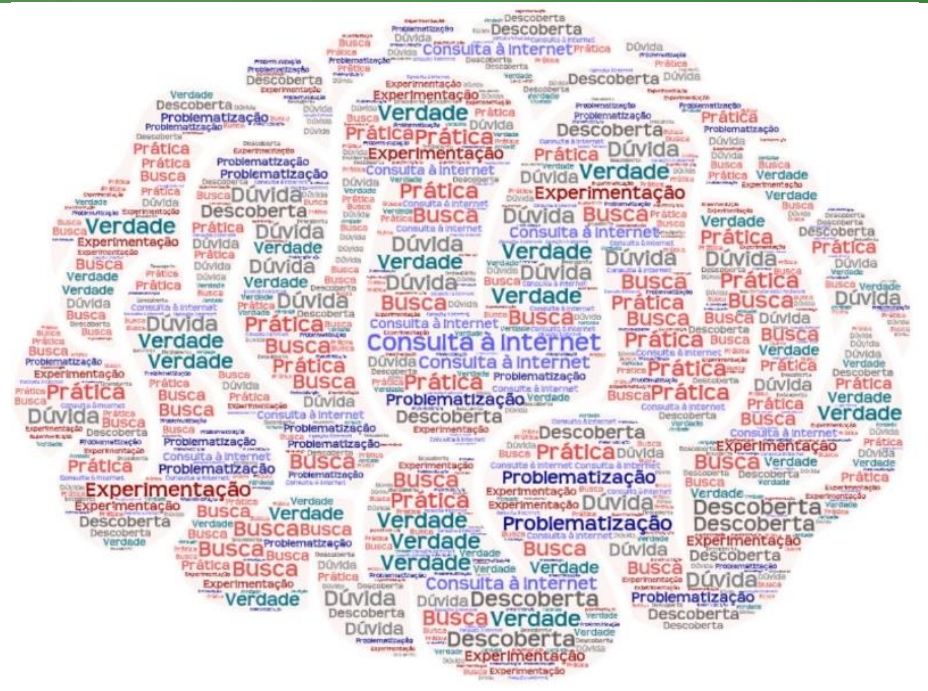

Figura 4 - Palavras recorrentes no discurso dos professores acerca da pesquisa como estratégia de ensino.

Consulta à Internet (23) foi a expressão mais utilizada para definir pesquisa escolar, tanto como estratégia de consulta em planejamento de atividades investigativas, em uma ação docente de procura por sugestões, quanto como uma ação discente, quando a pesquisa é uma proposição educativa. As falas de Clarice: "Pesquiso na Internet novos textos que me auxiliem a despertar os alunos para a aprendizagem sensível da Língua Portuguesa”, de Camila: "Eu leio muito, eu pesquiso muita coisa no Youtube $^{\circledR}$, na Internet, e eu estou sempre tentando conversar com os meus pares pra tentar articular esses projetos de uma forma que a arte não fique isolada”, ou de Mariah: "Quando eu não sei alguma coisa que tenho que adaptar para eles, pesquiso na Internet: jogos, exemplos de atividades e teoria"; exemplificam como esse grupo associa intimamente pesquisa à consulta de material digital.

De acordo com Oliveira e Chapani (2017) é bastante presente entre professores, a concepção de pesquisa enquanto busca mais elaborada, bem diversa do seu potencial crítico-avaliativo. A não problematização dessa concepção, pode vir a transformar a pesquisa docente em "uma 'caçada à atividade mais interessante', variante da didática fornecedora de modelos 'a serem reproduzidos' [...] e utilizados nas atividades diárias da escola (PICONEZ, 1991, p.23)" ou à estratégia avaliativa mais “em moda”.

As palavras: experimentação (14), verdade (10) e prática (16) são utilizadas diversas vezes para definir pesquisa em sala de aula. Em suas declarações os colaboradores transparecem uma visão pragmática e positivista tradicionalmente associada à Ciência, por conferirem à pesquisa, um caráter eminentemente científico e 
detentor de verdades incontestáveis (BACHELARD, 1977). Luíza, professora alfabetizadora nos Anos Iniciais, expõe essa visão quando questionada sobre a maneira como desenvolve aulas de Ciências com os pequenos: "Eu pesquiso na Internet e em livros, atividades que sejam interessantes para eles, e me informo se não estou falando alguma besteira. Mas assim, experimentos e ciência, mesmo, quem faz com eles é a professora do laboratório de Ciências".

Descoberta (7), dúvida (4) e problematização (3), ainda que pronunciadas relativamente com menos frequência, anunciam a existência nesse grupo, de colaboradores que já entendem a pesquisa como decorrente de questões e dúvidas, sejam elas empíricas ou não. Newton, professor de Física, transparece tal compreensão ao afirmar: “As aulas práticas são importantes para o desenvolvimento de pesquisa com os alunos. Nelas eles descobrem novidades sobre o mundo da Física e conseguem fazer perguntas mais relacionadas com o dia a dia". Cabe ressaltar ainda, que estas palavras surgiram no discurso dos professores doutores e mestres, evidenciando mais uma vez, que a intimidade com a ação investigativa se alimenta da vivência em pesquisa.

Problematização - dúvida, questionamento -, argumentação e comunicação formam o tripé que sustenta o Educar pela pesquisa. Segundo Moraes, Galiazzi e Ramos (2002), a pesquisa como princípio educativo baseia-se em situações problematizadas pelos atores da educação, que a partir da análise argumentativa e validação por meio da discussão e comunicação permanentes, constroem aprendizagens autônomo-críticas. Bachelard (1996; 1977) afirmava que o conhecimento, assim como a ciência, é dinâmico, sujeito a retificações, questionamentos e diálogos racionais, que levam o espírito científico ao júbilo, feliz por compreender fenômenos que despertaram sua curiosidade indagadora.

O desenvolvimento da pesquisa enquanto processo educativo, insatisfeito com a estagnação de saberes, enfrenta obstáculos tanto por parte dos docentes quanto por parte dos discentes, os quais foram relatados pelos professores-colaboradores. As palavras mais repetidas nesses relatos, foram sistematizadas no gráfico representado pela figura 5: 


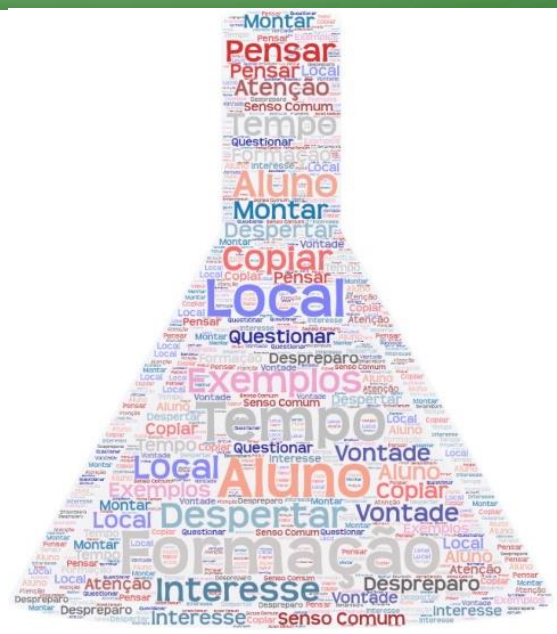

Figura 5 - Palavras recorrentes no discurso dos professores sobre empecilhos à utilização de pesquisa como estratégia de ensino.

Duas palavras: aluno (23) e tempo (18) novamente ocupam lugar de destaque. Entretanto, nessa categoria encontram-se associadas a despertar (17), interesse (11), e local (15). Em seus discursos, os colaboradores conferem à pesquisa escolar grande potencial para despertar o interesse dos alunos, entretanto o tempo exíguo e a ausência de locais adequados, segundo eles, dificultam que se torne uma atitude pedagógica cotidiana. Demo (1996, p. 12) relata que:

A pesquisa como atitude cotidiana [...] não pode ser vista como algo que cabe num momento e outro não, ou em certos ambientes especiais, mas como atitude típica, que faz parte de nossa maneira de ser e ver permanentemente. [...] é a prática consciente, crítica e ativa de modificações socioculturais.

Dessa forma, o autor dissocia pesquisa e aulas específicas de ciências, concepção demonstrada pelos colaboradores e reforçada pela palavra experimentação, apresentada em destaque na categoria anterior, além lhe conferir relevância sociocultural.

Nem todos os colaboradores associam pesquisa escolar às Ciências, esta característica é mais presente entre as pedagogas. Por outro lado, os professores colaboradores que lecionam nos Anos Finais e no Ensino Médio entendem a pesquisa como possível estratégia de ensino para as diversas disciplinas escolares. No discurso dos licenciados, sobressaem as palavras: copiar (13), atenção (8), pensar (3) e vontade (10) como atitudes discentes que emperram o desenvolvimento da pesquisa.

A afirmação de Cecília: "Os alunos não têm vontade de pesquisar, não param nem para pensar, nem para prestar atenção no que estão pesquisando e acabam entregando cópias literais de textos da internet como resultado da pesquisa”, exemplifica o discurso habitual dos professores colaboradores que lecionam em variadas áreas de conhecimento. Oligurski e Pachane (2010) vinculam o comportamento descrito por Cecília ao hábito mantido por professores e estudantes, de uma prática 
escolar na qual se busca por informação e conhecimento em leituras orientadas, culminando o processo, com a avaliação de um trabalho composto por recortes copiados desses textos de referência.

Dificuldades alusivas à formação (22) foram relatadas em discursos que também citavam exemplos (16), despreparo (10) e montar (7). Transcreve-se, a seguir, as afirmativas de Zizi e Ana, como exemplos desses discursos: "Eu não tenho preparo para trabalhar assim, na faculdade não me ensinaram e essas formações continuadas são só embromação (ZIZI)". "Eu queria que as formações da secretaria me trouxessem exemplos de atividades interessantes e práticas, me ensinassem a montar experimentos legais, que chamassem a atenção das crianças(ANA)".

Em relação à formação do professor em exercício, Ghedin (2004) recomenda que sejam promovidos momentos de integração, nos quais se privilegiem reflexões, discussões teóricas, compartilhamento e problematizações das práticas docentes em lugar dos tópicos administrativos e burocráticos costumeiros, muito provavelmente, a "embromação", citada por Zizi. Enquanto Silva (2011) descreve a conscientização e ressignificação das dificuldades, bem como a construção de soluções para estas, como abordagens necessárias ao desenvolvimento profissional mediado por formações continuadas. Seguindo estas proposições pode ser que as formações docentes desmistifiquem a abordagem pragmática, embasada em "modismos" da prática docente (PICONEZ, 1991), descrita na fala de Ana.

Duas palavras: questionar(1) e senso comum (3) se apresentaram nas falas de alguns professores. Colega cita a possibilidade de abordar a prática argumentativa como ponto fundamental para a pesquisa em sala de aula e Suzane coloca o embate entre conceitos científicos e senso comum, como uma das maiores dificuldades para a prática pedagógica que se apoia na pesquisa. Com estas falas, Colega apresenta conhecimento consistente em relação aos pressupostos do Educar pela pesquisa e Suzane, a preocupação com o fortalecimento de um dos obstáculos epistemológicos propostos por Bachelard (1996), bastante presente no cotidiano escolar.

\section{5. À GUISA DE REFLEXÃO}

A academia, já há alguns anos, reconhece a importância e recomenda a formação de docentes pesquisadores como estratégia promotora de progressos na Educação Básica. Todavia, os professores permanecem compreendendo a pesquisa como atividade 
externa ao seu cotidiano profissional, incapazes de reconhecerem-se como potenciais pesquisadores (FREIRE, 1996).

O histórico de formação do professor influencia positivamente, na participação em pesquisa. Aqueles cuja formação inicial foi na área de licenciatura demonstram maior intimidade e motivação, enquanto os graduados em Pedagogia, mostram-se inseguros quanto a desenvolverem-se pesquisadores, em contraste com os esforços atuais de formar professores-pesquisadores, promovido pelo PIBID. Todavia, os professores que se propõem a continuar pesquisando, mesmo que simultaneamente à atuação docente, procuram pesquisar em áreas especializadas, derivadas da área disciplinar inicial e não, em relação ao Ensino ou à Educação.

O professor entende a pesquisa como estratégia de aprimoramento de sua prática, não para realização pessoal, mas para a realização educativa discente. O caminho para a formação do docente pesquisador passa pela reflexão, entretanto, o conceito de reflexão da prática, para a maioria desses participantes, limita-se a aspectos pragmáticos. $\mathrm{O}$ corpo discente é centro e objeto das pesquisas pedagógicas docentes, as quais, geralmente configuram-se como busca de atividades vantajosas ou interessantes para os alunos. Professores não cogitam a reflexão e a pesquisa, como fatores que possam contribuir significativamente para sua subjetivação como produtor de conhecimento. Ainda, por reconhecerem-se despreparados, buscam auxílio em relação às prerrogativas metodológicas de uma investigação.

Tanto a atitude pesquisadora quanto a prática investigativa são ações contínuas, decorrentes do hábito cotidiano de pesquisa. Para se apropriar da pesquisa em seu fazer pedagógico, o professor necessita conviver e vivenciá-la como constituinte de sua subjetividade.

O cotidiano profissional discente afeta também a motivação para o professor empreender pesquisas de sua própria prática. Essa influência, por vezes apresenta-se como positiva, em busca de aprimoramento das estratégias de ensino ou promoções no quadro de carreira, e por outras vezes, é negativa, evidenciando falta de tempo, de subsídios teóricos e financeiros ou sobrecarga de trabalho.

Por todos esses dados aqui discutidos, podemos considerar que é longa e árdua a caminhada em direção à formação de professores pesquisadores e reflexivos, capazes de 
empreender a pesquisa em seu cotidiano, tanto como atitude profissional, quanto enquanto princípio educativo.

Autores referência, e os resultados dessa pesquisa, apontam modificações na abordagem das formações continuadas, como uma das estratégias nessa direção. Independente de quais outras estratégias se apresentem futuramente, há que se considerar o desenvolvimento de pesquisas educativas como fatores de grande relevância para fortalecer a autoestima e a inciativa docentes, fazendo com que o professor abandone o posto de mero transmissor de saberes, assumindo-se também como produtor.

Reconhecendo-se pesquisador e dessa maneira, promovendo sua própria autonomia e dos estudantes com os quais mantém contato, esse novo professor desenvolverá a capacidade de criticar o status quo, ampliando seu campo sociocultural de atuação, assumindo-se produtor de conhecimentos valiosos, não só para si e seus estudantes, mas também para toda a comunidade em que se encontra inserido.

\section{REFERÊNCIAS}

ANDRÉ, M. (Org.) O papel da pesquisa na formação e na prática dos professores.11 Ed. Campinas: Papirus, 2010.

BACHELARD, G. A formação do espírito científico. Rio de Janeiro: Contraponto, 1996.

BACHELARD, G. Estudos. Tradução de Estela dos Santos Abreu. $1^{\text {a }}$ ed. - Rio de Janeiro: Contraponto, 1970.

BACHELARD, G. O Racionalismo aplicado. Rio de Janeiro: Zahar, 1977.

BACHELARD, G. A poética do espaço. São Paulo: Martins Fontes, 2003.

BRASIL. Parecer n ${ }^{\circ}$ 009/ 2001, de 8 de maio de 2001. Dispõe sobre Diretrizes Curriculares Nacionais para a Formação de Professores da Educação Básica, em nível superior, curso de licenciatura, de graduação plena. Diário Oficial [da República Federativa do Brasil], Brasília, DF, 8 de maio de 2001. Disponível em <http://portal.mec.gov.br/cne/arquivos/pdf/009.pdf > Acesso em: 14 jun. 2020.

BRASIL. Decreto no 7.219, de 24 de junho de 2010. Dispõe sobre o Programa Institucional de Bolsa de Iniciação à Docência - PIBID e dá outras providências. Diário Oficial [da República Federativa do Brasil], Brasília, DF, 25 jun. 2010. Disponível em <http://www.planalto.gov.br/ccivil_03/_Ato2007-2010/2010/Decreto/D7219.htm > Acesso em: 14 jun. 2020.

CONTRERAS, J. A autonomia de professores. São Paulo: Cortez, 2002.

CORTIZO, T. L. Angústia do professor no cenário contemporâneo: Afeto manifesto no saberfazer. In: XVI ENDIPE - Encontro nacional de didática e práticas de ensino, 2012, Campinas. Disponível em: < http://endipe.pro.br/ebooks-2012/3018c.pdf> Acesso em: 02 de ago. de 2020.

DEMO, P. Pesquisa: princípio científico e educativo. São Paulo: Cortez. 1990.

DEMO, P. Educar pela pesquisa. São Paulo: Autores Associados, 1996. 
DRIVER, R; et. al. Construindo conhecimento científico na sala de aula. Química Nova Escola, n. 9, pp. 31-40, 1999.

ENGEL, G.I. Pesquisa-ação. Educar, v. 16, pp. 181-191, 2000.

ESTEBÁN, M. T.; ZACCUR, E. (Orgs.) Professora-pesquisadora: uma práxis em construção. Rio de Janeiro: DP\&A, 2002.

FÁVERO, A. R.; TONIETO, C. Mitos e potencialidades da interdisciplinaridade: reflexões sobre um tema emergente. Acta Sci. Educ., v. 42, e38982, 2020

FONTANA, M. J.; FAVERO, A. A. Professor reflexivo: uma integração entre teoria e prática. Revista de educação do Ideau. V. 8, n. 17, 2013.

FREIRE, P. Pedagogia da autonomia: saberes necessários à prática docente. São Paulo: Paz e Terra, 1996.

GARCIA, M. M. A. Didática e Trabalho Ético na Formação Docente. Cadernos de Pesquisa, v. 39, n. 136, 2009, pp. 225-242.

GERHARDT, T. E.; SILVEIRA, D. T. Metodologia de Pesquisa. Universidade Federal do Rio Grande do Sul. Porto Alegre: Editora da UFRGS, 2009.

GHEDIN, E. A Pesquisa como Eixo Interdisciplinar no Estágio e a Formação do Professor Pesquisador - Reflexivo. Olhar de professor, v.7, n.2, p. 57-76, 2004.

KIEREPKA, J. S. N.; ZANON, L. B. Problematização e reconhecimento de teorias e práticas de professores em formação para o ensino de Ciências com foco no educar pela pesquisa. Revista Insignare Scientia-RIS, v. 2, n. 1, p. 1-20, 2019.

LEITE, J. C.; MAGALHÃES JR. C. A. O.; RODRIGUES, M.A. Argumentações de um grupo de professores acerca do uso de atividades investigativas. Revista Insignare Scientia-RIS, v. 1, n. $1,2018$.

LISTON, D. P.; ZEICHNER, K. M. Teacher Education and the social conditions of schooling. Nova York: Routledge, 1991.

LOPES, A. R. C. Contribuições de Gaston Bachelard ao Ensino de Ciências. Enseñanza de las Ciencias, v. 11, n. 3, p. 248-274, 1993.

LÜDKE, M. O professor, seu saber e sua pesquisa. Educação \& Sociedade, v. 22, n. 74, pp. 77-96, 2001.

LÜDKE, M.; ANDRÉ, M. Pesquisa em Educação: Abordagens Qualitativas. São Paulo: EPU. 1986.

LARROSA, J. Tecnologias do eu e educação. In: SILVA, T. T. da. (Org.). O sujeito da educação: estudos foucaultianos. Petrópolis: Vozes, 2011, pp. 35-86.

LOGUERCIO, R.Q.; DEL PINO, J.C. Os Discursos Produtores da Identidade Docente. Ciência \& Educação, n. 9, p. 17-26, 2003.

MINAYO, M. C. S. Pesquisa social: teoria, método, criatividade. Petrópolis: Vozes; 1994.

MORAES, R.; GALIAZZI, M. C. Análise textual discursiva. Ijuí: Editora UNIJUÍ. 2007.

MORAES, R., GALIAZZI, M.C. e RAMOS, M.G. (2002). Pesquisa em sala de aula: fundamentos e pressupostos. En Moraes, R. e Lima, V.M.R. (Orgs.). Pesquisa em Sala de Aula: tendências para a Educação em Novos Tempos (pp. 9-24). 2. ed. Porto Alegre: EDIPUCRS.

MOREIRA, M. A. O professor-investigador como instrumento de melhoria do ensino de ciências. Em Aberto, 7(40), 43-54. 1988.

NUNES, D. R. P. Teoria, pesquisa e prática em educação: a formação do professorpesquisador. Educação e Pesquisa, São Paulo, v. 34, n. 1, p. 97-107, 2008.

OLIVEIRA, D. X.; CHAPANI, D. T. A pesquisa na formação em exercício de professores de ciências e biologia. Ensaio Pesquisa em Educação em Ciências, vol. 19, pp. 1-19, 2017. 
OLIGURSKI, E. M.; PACHANE, G. G. A possibilidade de incorporar a pesquisa na prática cotidiana do professor do ensino fundamental. Educação em Revista, v.26, n.2, p.249-276, ago. 2010.

PICONEZ, S. C. B. A prática de ensino e o estágio supervisionado: a aproximação da realidade escolar e a prática da reflexão. In: PICONEZ, S. C. B. (Coord.) A prática de ensino e o estágio supervisionado. Campinas: Papirus, 1991, p. 15-38.

SCHÖN, D. Educando o profissional reflexivo: um novo design para o ensino e a aprendizagem. Porto Alegre: Artes Médicas, 2000.

SILVA, J. C. M. Formação continuada dos professores: visando a própria experiência para uma nova perspectiva. Revista Iberoamericana de Educación, v. 55, n. 3, p. 1-11, 2011.

TRIPP, D. Pesquisa-ação: uma introdução metodológica. Educação \& Pesquisa, v. 31, n. 3, pp. 443-466, 2005.

ZEICHNER, K. M. Para além da divisão entre professor-pesquisador e pesquisador acadêmico In: GERALDI, Corinta M.; FIORENTINI, Dario \& PEREIRA, Elisabete M. (orgs.) Cartografia do trabalho docente: professor(a)-pesquisador(a). Campinas, Mercado de Letras/ABL, 1998. pp. 207-236.

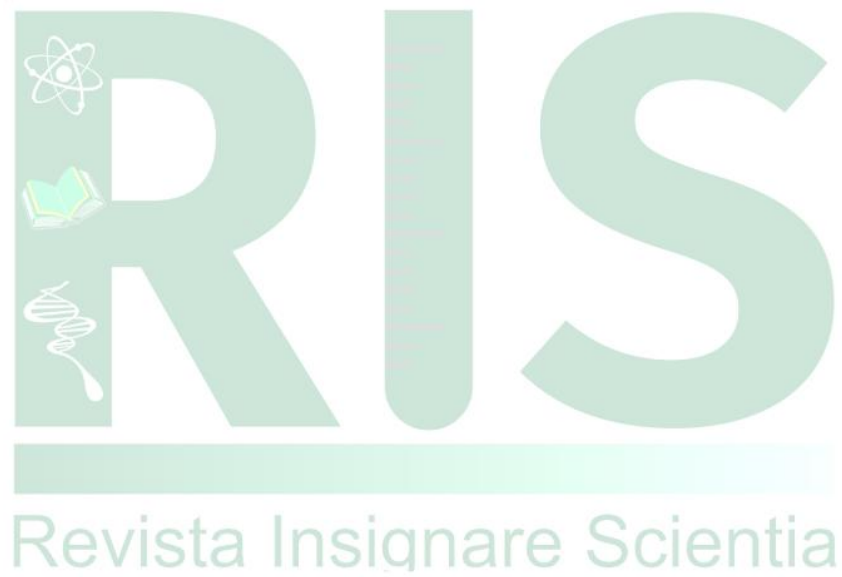

